\title{
Library Transformation Based on Social Inclusion in Accelerated Covid-19 Pandemic Treatment
}

\author{
Edi Wiyono* \\ Politeknik STIA LAN Jakarta \\ Jakarta, Indonesia \\ *ediwiyono@gmail.com
}

\begin{abstract}
Libraries based on social inclusion are libraries that facilitate communities to develop their potential by viewing cultural diversity, willingness to accept change, and offering opportunities to strive for, protect and advocate culture and human rights. The national library performs a transformation program for libraries based on social inclusion in an effort to improve literacy in communities. It has a purpose to create societies to thrive through the transformation of libraries based on social inclusion. More specifically the program has a feature :1). Improving the quality of library service. (2). Improving the use of services by communities according to the needs of the people. 3). Stakeholder commitment and support toward the sustainable transformation of the library. The program begins in 2018, with a coverage of 160 counties/cities with 800 villages. The program in 2020 is carried out during the pandemic and has proved to be capable of empowering various classes of society and of being the solution to economic problems. There were 10,434 community outreach activities with a total of 279,437 participants. 1,082 advocacy activities are carried out to build support and policies for the library and 147 activities are undertaken to promote the regulation that promotes the transformation of libraries. With this program, the results are: 1 . There is a significant influence between library service program intervention and library progress 2 . There is ahigh influence between the progress of library services and the impact (intermediate impact) felt by the community 3 . This program is considered to be cost effective, which is from the cost the amount issued produces a benefit ratio of 1.24 . This programis considered effective in terms of the time and approach used and can be extended to other areas to expand the benefits of libraries for the community.
\end{abstract}

Keywords-literacy, library, Covid-19, national library of Indonesia

\section{INTRODUCTION}

Data BPS shows that there are still 9.8 percent of people whose lives have not been prosperous or listed as poor [1]. Poverty is a state where there is an inability to meet such basic needs as food, clothing, shelter, education, and health. Poverty can be caused by a scarcity of essential items, or access to education and employment is scarce.
The cause of poverty is partly because of the lack of access to information caused by the following factors: 1 . Lack of connectivity in material circumstances and one's ability to access information related to technology, information and communication 2. Low content where the lack of qualified information and the lack of access required is available. 3 . The low aspect of human/human being is the inability to obtain useful information through education, experience and contextual reference is that one indicator for assessing literacy levels, among other things, through a pensive culture that reflects the interests and ease of society's access to information.

According to data published by MSBP in 2018 [2], people aged 10 and older read beyond the holy scriptures either print or new electronics at 45.72 percent while Internet access still stands at $43.47 \%$. And this shows the importance of improving public literacy by extending access to information and knowledge to the rest of the country. Talking about literacy will be linked to education. Literacy is every human right and provides tangible benefits, which are obtained through both school-education and adult programs. Literacy programs for people today produce benefits that go beyond the results of school education.

UNESCO states that literacy programs for adults emerge to yield several benefits, particularly building self-esteem and empowerment, with a financing mechanism that is just as effective as primary school education [3]. But data shows through an international study, more than $55 \%$ of Indonesians who are completing their education is that functionally fails to function or is less productive. This figure is much larger than the 14 percent in Vietnam as well as the figures in economic co-operation and development (OECD), by $20 \%$.

The Indonesian people who functionally develop tend to end up in jobs with low productivity. It has been mentioned above that reinforcement of literacy, innovation and creativity is one of the main pillars in the development of human resources. And development of human resources is a crucial factor in development growth that affects poverty rates in Indonesia. Literacy is a tool for learning and social practice that can build critical, creative and caring individual character for others and their environment. And libraries play an important role in informed, innovative, creative and characterless 
societies. Libraries have a fairly signific covid-19 with activities and empowerment to boost society's economy. Innovative activities have been successfully carried out in a number of libraries as recipients of the impact and benefits of the social inclusion and inclusion programs.

\section{THE TRANSFORMATION OF LIBRARIES BASED ON SOCIAL INCLUSION}

In the report on the Implementation of the Social Inclusionbased Library Transformation Program, 2018-2019 explains that UIL (UNESCO Institute for Educational Learning) policy brief 6-2016 states the existence of libraries to support national literacy efforts [4]. Literacy is not only related in the conventional sense of ability to read and write, but it can also be translated to address problems, improve quality of life and well-being. Literacy contributes to economic development and growth because it is closely linked to profit literal and numerical.

Literacy can contribute to economic development and prosperity. Besides its literal and numerical prowess, literacy can also enhance economic competitiveness. Libraries, reading parks and higher education should begin to change the literacy paradigm into the empowering literacy paradigm of society. Ifla 2018, says libraries support all the SDGS 'goals (library supports all the SDGS' goals).

Kranich [5], argues that libraries, either real or virtual, create social capital by offering in common where compas and free associations can be found in a pathetic public place where members of society can work together on issues or personal issues as well as communities. Libraries can create social capital by offering diverse programs and activities that can facilitate the plurality of society with over differences, cultural backgrounds, economic status, and interests; And connect with other institutions in the community that can improve literacy.

Bourke [6] argued that the library had the potential to build partnerships with the public business of other government organizations, schools, and social organizations in order to expand library services and build relationships to exclusive and marginal groups.

Most [7] study of rural public libraries in Florida found that they build social capital by providing the same non-commercial meeting places for different communities as a source to enable them to build and maintain relationships.

Heuertz [8] study of village libraries and community development also demonstrates similar findings, especially on the effects of outreach, the unifying of communities from different groups, and the library's ability to encourage people's sense of belonging to the library.

Libraries based on social inclusion are libraries that facilitate communities in developing their potential by viewing cultural diversity, willingness to accept change, and offering opportunities to strive for, protect and advocate culture and human rights. The national library performs a transformation program based on social inclusion in an effort to improve literacy in communities. It has a purpose to create societies to thrive through the transformation of libraries based on social inclusion.

More specifically the program has a feature: 1. Improving the quality of library service. 2 . Improving the use of services by communities according to the needs of the people. 3 . Stakeholder commitment and support toward the sustainable transformation of the library.

To accomplish the above goal, the program performs five main activities: 1 . Hiring building through technical guidance, mentoring/guiding routine and sustainable, and peer learning meeting at the national level and province 2. Provide support for increased information services through collections of library materials, computers and Internet 3 . Building multistakeholder synergy at the national level, province, district, to village level 4. Monitoring, evaluation, and learning 5. The publication to build a public awareness and a library service promotion.

To achieve that purpose, in its implementation, the regional library and the village library of the partners program employ 3 (three) the main strategy: 1) strategy of community outreach activities to facilitate community needs; 2 ) information services access strategies through library collections, computers and the Internet; And 3) advocacy strategies and building partnerships for sustainability.

In its implementation there are good practices and benefits beginning to be felt by society. Empirical evidence is needed to know the effectiveness of programs and benefits acquired by communities and library institutions themselves. There is also need for factual information on the aspects that are progressing well and those that still need to be corrected. It therefore requires an evaluation to measure implementation effectiveness, benefits obtained, and to identify improvement recommendations.

\section{THE LIBRARY IS BASED ON SOCIAL INCLUSION IN THE PANDEMIC}

In his presentation, Dr. Ir. Subandi Sardjoko, MSc Deputy for Human Development, Society and Culture on Social Inclusion-Based Library Transformation in Accelerating Handling of the Covid-19 Pandemic explained that The covid19 case in Indonesia is growing and increasing tremendous pressure on health-care systems; Increasingly points to weak points of health systems, such as surveillance systems, test capacity, trace and treat, and the ability to provide domestic health tools, drugs, and vaccines [9].

\section{A. Literacy and Pandemic}

Literacy skills affect whether health information is better acceptable to society and thus curb the number of victims. Countries with lower literacy rates have a higher risk of pandemics than others. 


\section{B. Pandemic and Infodemic}

literacy levels affect one's attitude in determining response to the pandemic. Public panic sets in as a sudden reaction that is often triggered by widespread false information. Literal people will always do a confirmation of the truth of the information obtained.

\section{Literacy and Health}

People with better informed literacy tend to be more aware of the vulnerability of pandemic conditions. They'll be able to detect the symptoms independently, fluent in communicating with the medical team, thus always ready to protect themselves. As a library's empowerment center facilitates all community groups to utilize resources of information and knowledge in order to develop and improve life skills.

\section{CONCLUSION}

- Reinforcement of policy ecosystems: strengthening literacy based is optimally possible if supported by good literacy ecosystems, including access and quality of literacy content, the tools and infrastructure of literacy, regulation and institutional services.

- The increase in the stakeholder's synergy is the result of the increase in the number of shares of the company's shareholders' meeting on Wednesday.

- The replication of the library transformation policy based on social inclusion: the development of libraries based on social inclusion: the development of libraries and the world effort into replicating libraries based on social inclusion.

- Optimizing the role of village libraries and TBM: village libraries and reading parks need to continue optimizing their roles as information and knowledge centers, as well as empowerment centers for liter-based societies to move people from the deep.

- Strengthening synergy of funding: synergy of finance transforms library services based on social inclusion through optimizing other funding resources: village fund, education and several other resources.

\section{REFERENCES}

[1] National Library of Indonesia, Implementation Report Of The Revitalization Of The Library Program Through Transforming Library Services Based On Social Inclusion, 2018.

[2] Badan Pusat Statistik, Survei Sosial Ekonomi Nasional (SUSENAS), 2018. [Online] Retr=rieved from: https://sirusa.bps.go.id/sirusa/index.php/dasar/pdf?kd=1581\&th=2018

[3] D.A. Wagner, "What happened to literacy? Historical and conceptual perspectives on literacy in UNESCO," International Journal of Educational Development, vol. 31, no. 3, pp. 319-323, 2011.

[4] A. Grizzle, P. Moore, M. Dezuanni, S. Asthana, C. Wilson, F. Banda, and C. Onumah, "Media and information literacy: policy and strategy guidelines," UNESCO, 2014.

[5] N. Kranich, "Libraries Create Socialcapital," Library Journal, vol. 26 no. 19 , pp. 40-41, 2001

[6] C. Bourke, "Public libraries: Building social capital through networking," Australasian public libraries and information services, vol 18, no. 2, pp. 71-75, 2005

[7] L.R. Most, The rural public library as place in North Florida: A case study. PhD.Dissertation, Florida State University, USA Neuman, W Lawrence, Social Research Method: Quantitative and Qualitative Approach, seventh edition, 2014

[8] L. Heuertz, Rural libraries building communities. PhD Dissertation, University of Washington, USA, 2009.

[9] S. Sardjoko, Social Inclusion-Based Library Transformation in Accelerating Handling of the Covid-19 Pandemic explained, 2020 